\title{
Investigating the Colombian University System: What Does the Future Hold?
}

\section{Sakkal, Ali}

Department of Education, Wake Forest University, United States of America

\begin{abstract}
While there are encouraging recent narratives of Colombia as a booming center of innovation and economic growth, this positive commentary does not always match accounts regarding the country's universities. This study investigates Colombia's drastically changing university system through an analysis connecting larger policy initiatives to the sentiments and perceptions of stakeholders at the ground levels of university functions. The focus here is on recent policy decisions, what they look like at the ground level, and how some of these revisions compare to university trends elsewhere. This investigation of various stakeholders at a large public university in Colombia sheds light on growing student and university debt, modifications in university funding, the rapid growth of low-quality private universities, changing roles of faculty, and issues of student access. Recommendations include a more concerted use of student loan disbursement and sustained investment in the public universities.
\end{abstract}

Keywords: Privatization; University; Policy; Reform; Colombia; Loans. 


\section{Introduction}

Colombia is a unique context for investigating grand and recent educational policies at the ground level. Beginning in the early 1990s, a number of large educational reforms regarding the funding and overall organization of public universities restructured many of the previous approaches and regulations governing these institutions. The first of these regulations came in the form of Ley 30 in 1992, which drastically reduced government funding to public universities (Brunner et al., 2012), and required these institutions to be responsible for fundraising approximately half of their budgets (Izecson de Carvalho et al., 2013). Dicreto 1279 (2002), which aimed to appease many professors by rewarding them financially for their publishing as well being an attempt to quickly raise the status of Colombian universities on the international stage went into effect. Years down the road, it is believed to have caused much strain on public universities to pay the salaries of professors and has now caused a growing debt shortfall. Another reform, Ser Pilo Paga, would also be another policy change affecting the status quo in that student funding that had traditionally only followed students going to public universities could now follow students to the private university of their choice (Asmar \& Gómez, 2016). All of these monies are administered and controlled by The Colombian Institute of Educational Credit and Technical Studies Abroad (ICETEX) which, in a recent 2017 reform, has also been in charge of distributing monies to public institutions rather than the monies going directly to the public institutions as had been done previously.

These recent reforms, combined with the current narrative of Colombia (and especially Medellin) as a booming center of innovative and economic growth has in many ways affected the management and culture of university education. Current President Juan Manuel Santos learned firsthand that such proposals would not progress easily in Colombia with the 2011 protests forcing the president and The Ministry of Education to recall their proposed changes regarding more private monies entering public universities (El Espectador, 2011). A part of the issue is that Latin America is quite unique in how it values its university education. As early as the Córdoba Reforms of 1918, access to university education has been viewed as a "basic need" (Patrinos, 1990). However, today's reality in terms of the needs of a booming economy are not being met due to fairly low numbers of students that actually go onto post-secondary education (Brunner et al., 2012). Many advocates of privatization such as the World Bank and President Santos cite the need to increase private monies within public university education as the solution to university expansion (Patrinos, 1990). However, advocates against privatization also shed light on recent negative situations such as an influx of low-quality private universities and lowered research quality as being connected to aggressive privatization (Ibid.). 
While there are a number of large-scale quantitative reports regarding schooling populations (Brunner et al., 2012), there are virtually no extensive or deliberate studies that investigate the understandings and opinions of the stakeholders within Colombian universities today. This inquiry aims to provide more insight on the possible disconnect between policy-makers and the entities at the ground level of decision-making.

\section{Methods}

This study commenced with interviews of approximately ten subjects. These participants included university professors and administrators employed at one of the largest public universities in Colombia, Universidad de Colombia (pseudonym). Additionally, there were two interviews with education policy-makers at the national level. The author conducted numerous open-ended interviews over the course of five months. This initial series of interviews were analyzed through open coding before moving to an axial coding process to help categorize the open coding terms into single categories most mentioned by participants (Strauss 1987, 64).

\section{Analysis and Findings}

The themes most addressed by participants are analyzed in detail in the following sections. A significant point of interest is there were very few discrepancies between the parties interviewed. All participants, whether professors, administrators, or policy-makers were mostly unified in their sentiments as to the current issues.

\subsection{The Money Problems are by Design}

The effects of Ley 30 (1992) were felt by all professors and administrators on a daily basis. With the responsibilities of public universities now including finding their own sources of income, both professors and administrators regularly addressed that part of their job was now fundraising. Participants now regularly spend half their time or more locating grant monies while still having to keep up with what have been traditionally more teaching based positions. Participants went on to partially condemn Dicreto 1279 (2002), which generated a significant cash flow to professors based on their publications as an unsustainable reform that further stressed the budgets of public institutions. Through a unique reform, this decree raised future salaries for every article published. While the interviewed professors wholly acknowledged that this raised their salaries significantly, they were quick to concede that this has contributed much strain on public universities to pay salaries and has now caused a growing debt shortfall. The belief that such reforms were orchestrated to "divide and 
conquer" the once powerful professor unions and run these institutions into debt is in the minds, and on the tongues, of many professors and administrators.

\subsection{The Rapid Growth of the Private System is also by Design}

Ser Pilo Paga was a reform that changed the status quo, allowing funding that traditionally followed only students attending public universities to now follow them to private institutions. All interviewed parties were open about that fact that it's much easier to attend private universities, with entrance requirements being significantly lower. Additionally, all participants seemed to have a clear understanding of Colombia's tiered university system catering to particular parts of the population: elite private universities for the wealthy, large public universities for the upper middle class, and low-cost low-quality private institutions for the lower middle class. The rapid growth of low-quality private institutions sheds light on the fact that these institutions often hire faculty without advanced degrees and fail to meet high quality accreditation procedures (Brunner et al., 2012). All participants looked down upon these institutions, with many referring to them as a waste of money for students. With public money now flowing into these institutions, many feel that the public too may also turn away from future support for all higher education institutions. In essence, participants viewed recent reforms as way to strengthen the public/private divide rather than ameliorate it.

\subsection{The Students are Paying the Real Price}

Connected to the issue of student access is the unique culture of Colombia for having student loans since the 1950s, a rarity in the region. However, student loans in Colombia did not traditionally help the most needy students, as they often went to higher income families (Patrinos, 1990). Study participants recognized the stresses on incoming students, the first of probably many more generations to have significant loan amounts with valid repayment concerns (Salmi, 2013). Even a short walk around campus at Universidad de Colombia makes clear that an accepted "black market" of students selling anything from tshirts to homemade crafts and snacks fills up most hallways and communal areas. This is the reality of paying for university for many students. While the narratives of growing university debt and stress has been quite common in the United States for a number of decades (Travis, 2103), this is the first time that many participants are seeing it within their populations. They note that it often affects student performance and the time that they are able to dedicate to their studies. 


\section{Recommendations and Conclusions}

The issues raised by the participants of this study are valid and it is imperative that future Colombian education policies address these gaps, lest they find themselves encountering the inflating debt situations arising in the United States (Travis, 2013) or Chile (Salmi, 2013). Additionally, as the cost of living in a stable Colombia continues to rise at a more rapid pace than salaries (Mejía, 2017), it is urgent that universities be the centers of progress and training for the jobs of the future.

With the rising costs of living as well as schooling in Colombia, we must be extremely cautious of how student loans are being disbursed, and ultimately, collected. Firstly, in a country like Colombia, loans must cover not only tuition, but also forgone earnings so that students are actually able to complete their education. However, with the larger loans needed to cover higher costs comes a rise in repayment difficulties. Without an incomecontingent provision, repayment can be a strain on the system (Salmi, 2013), but it can also leave Colombia's ICETEX loan system in a place where it continues to ignore the students that stand to benefit the most, as they are more reluctant to collect loans they may not be able to pay back. Therefore, there must be significant efforts to get sufficient funding to the least advantaged students and tie their repayment amounts to their future salaries.

The harsher reality for the students that need university the most in Colombia is that most of them will never get the chance to step on a university campus. Even when they are lucky enough to enter university, chances of graduation remain slim. As Carlos Alberto Casas Herrera of the University of Los Andes Education Research and Formation Center states, "out of 100 students [who] start primary education in Colombia, only 40 will finish the 11th grade. Out of those, 10 will enter the university, and only five will graduate.” (as cited in Izecson de Carvalho et al., 2013). The Government recognizes this and has set goals for half of Colombia's youth to continue their education after high school (World Bank, 2013). Such conditions make clear that the university cannot do it on its own. Pipelines linking secondary institutions to universities are a crucial step to bringing students into tertiary education.

Lastly, with private institutions growing at increased rates in Colombia, both in terms of quantity and student enrollments, government reforms and initiatives must make certain to not forget about their public universities. While the private institutions are generally cheaper to run, most are low-quality, they lack the quality control regulations of the public institutions, can close with little warning, and lack research programs (Patrinos, 1990). Additionally, private institutions rarely offer masters and $\mathrm{PhD}$ programs, with public institutions already struggling to produce sufficient numbers of students with advanced degrees. As Brunner et al. (2012) reported regarding one of Colombia's largest public universities, the University of Antioquia, with a population of more than 30,000 students, 
"had less than 300 students enrolled in its 23 doctoral programmes and graduated just 19 PhDs.” (p. 155).

If the narrative of Colombia as a place of innovation and growth is to come close to actualization in the coming years, the country will need to produce more graduates from high quality institutions and more graduates with advanced degrees. Looking at the Colombia of the past as well as today, a substantial majority of these individuals will be born of the country's public universities.

\section{References}

Asmar, P., \& Gómez, V. (2016). “Los alcances del 'Ser Pilo Paga’ son excesivamente limitados”. El Espectador. Retrieved from https://www.elespectador.com/noticias/educacion/los-alcances-del-ser-pilo-paga-sonexcesivamente-limita-articulo-600089

Brunner, J. J., Gacel-Avilà, J., Laverde, M., Puukka, J., Rubio, J., Schwartzman, S., \& Valiente, Ó. (2012). Higher Education in Regional and City Development: Antioquia, Colombia 2012. OECD Publishing.

El Espectador. (2011, November 16). Oficializan retiro de reforma a la educación. Retrieved from http://www.elespectador.com/noticias/educacion/oficializan-retiro-dereforma-educacion-articulo-311485

Izecson de Carvalho, A., Looi, Y., Saad, F., \& Sinatra, J. (2013, January 2). Education in Colombia: Is There a Role for the Private Sector? Retrieved from http://knowledge.wharton.upenn.edu/article/education-in-colombia-is-there-a-role-forthe-private-sector/

Mejía, D. (2017, January 20). Minimum wage to increase by 7\% in 2017. Retrieved from https://thebogotapost.com/2017/01/20/minimum-wage-increase-7-2017/

Patrinos, H. A. (1990). The privatization of higher education in Colombia: Effects on quality and equity. Higher Education, 20(2), 161-173.

Salmi, J. (2015). The challenge of sustaining student loan system: Colombia and Chile. International Higher Education, (72), 21-23.

Strauss, A. L. (1987). Qualitative analysis for social scientists. Cambridge University Press.

Travis, J. (2012). Privatizing American public higher education: racing down a slippery slope. Journal of Case Studies in Education, 4, 1.

World Bank. (2013, January 24). Colombia's Goal: More Success in Higher Education, More Opportunities for Youth. Retrieved from http://www.worldbank.org/en/news/feature/2013/01/24/colombia-more-success-inhigher-education-more-opportunities-for-youth 